\title{
ANALISIS PENGARUH KUALITAS APLIKASI SDMS TERHADAP KINERJA KARYAWAN YANG BERDAMPAK PADA PELAYANAN KONSUMEN DI PT. KJIU SUZUKI CIKARANG
}

\author{
Rini Malfiany \\ rini@rosma.ac.id \\ Manajemen Informatika \\ STMIK Rosma Karawang
}

\begin{abstract}
ABSTRAK
Aplikasi yang berkualitas akan memberikan dampak positif untuk karyawan dalam hal melakukan pekerjaannya. Hal ini akan berpengaruh baik juga kepada konsumen dalam hal pelayanan terhadap konsumen. PT. KJIU (Kebayaron Indah Utama) merupakan salah satu dealer resmi Suzuki di Cikarang yang melayani penjualan mobil suzuki dan servis kendaraan. Aplikasi yang ada di PT. KJIU semua sudah berbasiskan komputer dengan nama alikasinya SDMS (Suzuki Development Management System) seperti dari input data konsumen, riwayat service kendaraan, karyawan yang menangani konsumen yang service dan melakukan pengerjaan service semua sudah dimasukan dalam sistem sehingga di dalam pembagian insentif tidak akan mengalami kesalahan dalam hal jumlah penanganan dan pengerjaan. Metode analisis data yang digunakan adalah metode deskriptif dan metode verifikatif dengan jumlah populasi seluruh karyawan PT. KJIU yang menggunakan aplikasi SDMS dan sampel 180 konsumen untuk mengetahui tingkat kepuasan pelayanan. Hasil penelitian ini menunjukkan bahwa (1) Ada pengaruh positif antara kualitas aplikasi SDMS terhadap kinerja karyawan. (2) Ada pengaruh positif kinerja karyawan terhadap pelayanan konsumen pada PT. KJIU Suzuki Cikarang.
\end{abstract}

Kata Kunci : Kualitas Aplikasi, Kinerja Karyawan dan Pelayanan Konsumen

\section{PENDAHULUAN}

PT. Kebayoran Jaya Indah Utama (KJIU) didirikan pada tanggal 10 Agustus 1987 yang berlamat di Jl. Radio Dalam Raya No. 125 Kelurahan Gandaria Utara, Kecamatan Kebayoran baru, Jakarta Selatan 12140. Berekspansi k Cikarang Jawa Barat dan Kelapa Gading Jakarta Utara, yang masing-masing didirikan pada tanggal 20 Mei 2014 dan 1 Oktober 2018. Dengan jumlah karyawan sebanyak 150 orang tersebar di cabang-cabang. PT. Kebayoran Jaya indah Utama merupakan Dealer Utama Suzuki yang ditunjuk oleh ATPM PT. Suzuki Indomobil Sales.

PT. Kebayoran Jaya Indah Utama (KJIU) telah memiliki sistem berbasis komputer yang bernama SDMS (Suzuki Development Management System) yang terhubung dengan semua cabang KJIU. Dimana semua transaksi sudah masuk dalam sistem tersebut. Mulai yang berkaitan dengan konsumen, seperti data konsumen yang service, riwayat service kendaraannya semua lengkap masuk dalam sistem tersebut, termasuk dalam sisi karyawan nya, siapa yang mengerjakan service yang menangani konsumen semua di input dalam sistem, jika ada konsumen yang komplen dalam hal penganan service bisa terlohat siapa saat itu yang menangani mulai dari service advisor nya hingga mekanik yang mengerjakannya, hal ini juga berdampak pada pemberian insentif karyawan agar tidak salah dalam menghitung insentif karena insentif bergantung pada jumlah penangangan service.

Kualitas aplikasi yang baik merupakan salah satu parameter untuk mengukur berhasilnya sebuah sistem dibuat, tingkat kinerja karyawan sebagai pengguna aplikasi tersebut merupakan kunci dalam pengembangan potensi karyawan itu sendiri yang akan bermanfaat untuk pertumbuhan perusahaan salah satunya pada pelayanan konsumen, jika konsumen mendapatkan pelayanan yang memuaskan dari karyawan maka perusahaan juga akan berkembang pesat dan tidak akan sepi dari konsumen yang datang.

Berdasarkan penelitian tersebut, penulis ingin mengetahui pengaruh kualitas aplikasi terhadap kinerja karyawan yang akan berdampak pada pelayanan konsumen di PT. Kebayoran Indah Utama (KJIU) Cikarang.

\section{TINJAUAN PUSTAKA}

Menurut DeLone dan McLean (dalam Widodo et al.2016:164) mengemukakan bahwa kualitas sistem aplikasi merupakan karakteristik dari informasi yang melekat mengenai sistem aplikasi itu sendiri yang mana kualitas sistem aplikasi merujuk pada seberapa baik kemampuan 
perangkat keras, perangkat lunak kebijakan prosedur dari sistem aplikasi informasi yang dapat menyediakan informasi kebutuhan pemakai.

Moeheriono (dalam Rosyida 2010: 11) Dalam bukunya menyimpulkan pengertian kinerja karyawan atau defisi kinerja atau performance sebagai hasil kinerja yang dapat dicapai oleh seseorang aau kelompok orang dalam suatu organisasi baik secara kualitatif maupun secara kuantitatif, sesuai dengan kewewenangan, tugas dan tanggung jawab masing-masing dalam upaya mencapai tujmuan organisasi bersangkutan secara legal, tidak melanggar hukum dan sesuai dengan moral ataupun etika.

Buchari Alma (2013:243) menjelaskan bahwa Pelayanan adalah jasa atau layanan yang diberikan pada konsumen dalam hubungan dengan produk tertentu. Misalnya layanan menjawab pertanyaan-pertanyaan yang dilontarkan oleh para penlanggan, mencari pesanan yang diinginkan, mengatasi segala keluhan-keluhan pelanggan, perbaikan-perbaikan reparasi, melayani pelanggan yang datang untuk pramuniaga dan sebagainya.

\section{METODOLOGI PENELITIAN}

Metode analisis data yang digunakan adalah metode deskriptif dan metode verifikatif. Metode deskriptif. Sugiyono (2011:207) statistik deskriptif adalah statistik yang digunakan untuk menganalisis data dengan cara mendeskripsikan atau menggambarkan data yang telah terkumpul sebagaimana adanya tanpa bermaksud membuat kesimpulan yang berlaku untuk umum atau generalisasi.

Tujuan dari penelitian deskriptif adalah untuk membuat deskripsi, ciri-ciri, gambaran atau lukisan secara sistematis, faktual, dan akurat mengenai variabel kualitas jasa layanan, harga dan kepuasan konsumen. Dengan metode desktiptif ini akan terlihat gambaran dan keadaan variabelvariabel tersebut. Sedangkan metode verifikatif yaitu metode yang digunakan untuk menguji kebenaran dari suatu hipotesis yang dilaksanakan melalui pengumpulan data di lapangan.

Penelitian ini akan menguji pengaruh kualitas aplikasi terhadap kinerja karyawan yang berdampak pada pelayanan konsumen baik secara parsial maupun simultan. Adapun metode statistik yang digunakan untuk menganalisis hubangan antar variabel yang diteliti yaitu dengan menggunakan analisis jalur (path analisys) untuk menguji pengaruh secara parsial/individual yaitu pengaruh masing-masing dari variabel. Selain itu penelitian kausalitas ini untuk menguji pengaruh secara simultan dari variabel bebas yaitu (Independent) terhadap variabel terikat (Dependent). Penelitian ini untuk menguji pengaruh secara simultan kualitas aplikasi terhadap kinerja karyawanserta dampaknya pada pelayanan konsumen.

\section{HASIL PEMBAHASAN \\ 4.1 Uji Validitas}

Uji validitas merupakan suatu ukuran yang menunjukkan tingkat kevalidan suatu instrument penelitian. dibagi menjadi dua kategori untuk karyawan pengguna SDMS untuk mengukur kualitas aplikasi dan 180 responden dari konsumen untuk mengetahui kinerja karyawan dan pelayanan terhadap konsumen. didapat hasil analisis validitas yang dibantu dengan menggunakan SPSS, penulis dapat mengetahui bahwa kuesioner tersebut valid atau tidak valid dengan membandingkan nilai $r$ ( $r \geq 0,300$ : valid) atau ( $r \leq 0,300$ : tidak valid). Adapun hasil uji validitas ketiga variabel tersebut adalah sebagai berikut:

Kuesioner dibagi menjadi dalam tiga variabel yaitu, variabel kualitas aplikasi dengan 6 kueisoner, 5 variabel kinerja karyawan dan variable 5 variabel pelayanan konsumen, dengan jumlah pertanyaan 16 kuesioner. Ukuran validitas setiap pertanyaan, dapat dilihat pada tabel-tabel berikut: 1. Variabel Kualitas Aplikasi

Data yang diperoleh oleh peneliti dari hasil menyebar kuesioner kepada sampel yang jumlahnya 30 responden konsumen PT. KJIU Suzuki Cikarang, didapat hasil analisis validitas yang dibantu dengan menggunakan SPSS, penulis dapat mengetahui bahwa kuesioner tersebut valid atau tidak valid dengan membandingkan nilai $r$ kritis ( $r$ hitung $\geq 0,300$ : valid) atau ( $\mathrm{r}$ hitung $\leq 0,300$ : tidak valid). Adapun hasil uji validitas variable kualitas pelayanan tersebut ditunjukkan Tabel 1:

Tabel 1 Analisis Validitas Variabel Kualitas Aplikasi

\begin{tabular}{|c|l|c|c|c|}
\hline No & \multicolumn{1}{|c|}{ Pertanyaan Peneliti } & r Hitung & r Kritis & Kriteria \\
\hline 1 & Kelengkapan & 0,515 & 0,300 & Valid \\
\hline 2 & Relevan & 0,583 & 0,300 & Valid \\
\hline 3 & Akurat & 0,701 & 0,300 & Valid \\
\hline 4 & Penyajian Informasi (Format) & 0,700 & 0,300 & Valid \\
\hline 5 & Ketepatan Waktu & 0,814 & 0,300 & Valid \\
\hline
\end{tabular}




\begin{tabular}{|c|c|c|c|c|}
\hline No & Pertanyaan Peneliti & r Hitung & r Kritis & Kriteria \\
\hline 6 & Penggunaan & 0,804 & 0,300 & Valid \\
\hline
\end{tabular}

Sumber: Hasil Olah data Kuesioner, 2018

Berdasarkan Tabel 1, dari 6 butir pertanyaan, semua indikator variabel Kualitas Aplikasi dinyatakan valid, karena $r$ hitung lebih besar dari 0,300 ( $\mathrm{r}$ hitung $\geq 0,300$ ).

2. Variabel Kinerja Karyawan

Data yang diperoleh oleh peneliti dari hasil menyebar kuesioner kepada sampel yang jumlahnya 180 responden konsumen PT. KJIU Suzuki Cikarang, didapat hasil analisis validitas yang dibantu dengan menggunakan SPSS, penulis dapat mengetahui bahwa kuesioner tersebut valid atau tidak valid dengan membandingkan nilai $r$ kritis ( $\mathrm{r}$ hitung $\geq 0,300$ : valid) atau ( $\mathrm{r}$ hitung $\leq 0,300$ : tidak valid). Tabel 2 adalah hasil uji validitas variabel harga.

Tabel 2 Analisis Validitas Variabel Kinerja Karyawan

\begin{tabular}{|c|l|c|c|c|}
\hline No & \multicolumn{1}{|c|}{ Pertanyaan Peneliti } & r Hitung & r Kritis & Kriteria \\
\hline 1 & Kualitas Kerja & 0,507 & 0,300 & Valid \\
\hline 2 & Kuantitas Kerja & 0,597 & 0,300 & Valid \\
\hline 3 & Tanggungjawab & 0,594 & 0,300 & Valid \\
\hline 4 & Kerjasama & 0,744 & 0,300 & Valid \\
\hline 5 & Inisiatif & 0,668 & 0,300 & Valid \\
\hline
\end{tabular}

Sumber: Hasil Olah data Kuesioner, 2018

Berdasarkan Tabel 2, dapat diketahui bahwa dari 5 butir pertanyaan semua variabel harga dinyatakan valid karena $r$ hitung lebih besar dari 0,300 ( $\mathrm{r}$ hitung $\geq 0,300$ ).

3. Variabel Pelayanan Konsumen

Data yang diperoleh dari 180 responden konsumen PT. KJIU Suzuki Cikarang, didapat hasil analisis validitas yang dibantu dengan menggunakan SPSS, penulis dapat mengetahui bahwa kuesioner tersebut valid atau tidak valid dengan membandingkan nilai $\mathrm{r}$ kritis ( $\mathrm{r}$ hitung $\geq 0,300$ : valid) atau ( $\mathrm{r}$ hitung $\leq 0,300$ : tidak valid). Adapun hasil uji validitas variable pelayanan konsumen ditunjukkan pada Tabel 3.

Tabel 3 Analisis Validitas Variabel Pelayanan Konsumen

\begin{tabular}{|c|l|c|c|c|}
\hline No & \multicolumn{1}{|c|}{ Pertanyaan Peneliti } & r Hitung & r Kritis & Kriteria \\
\hline 1 & Bukti Fisik & 0,365 & 0,300 & Valid \\
\hline 2 & Keandalan & 0,435 & 0,300 & Valid \\
\hline 3 & Ketanggapan & 0,551 & 0,300 & Valid \\
\hline 4 & Jaminan & 0,475 & 0,300 & Valid \\
\hline 5 & Empati & 0,611 & 0,300 & Valid \\
\hline
\end{tabular}

Sumber: Hasil Olah data Kuesioner, 2018

Berdasarkan Tabel 3 dapat diketahui bahwa 5 butir pertanyaan variabel pelayanan konsumen dinyatakan valid karena $\mathrm{r}$ hitung lebih besar dari 0,300 ( $\mathrm{r}$ hitung $\geq 0,300$ ).

\subsection{Uji Reliabilitas}

Untuk mengetahui reliabilitas setiap variabel dalam penelitian ini, peneliti menggunakan alat bantu SPSS. Dengan menggunakan alat bantu SPSS, peneliti dapat mengetahui bahwa kuesioner tersebut reliable atau tidak reliable yang artinya $r>0,600$ atau $r<0,600$. Hasil uji reliabilitas ditunjukkan pada Tabel 4.

Tabel 4 Hasil Uji Reliabilitas

\begin{tabular}{|c|c|c|c|}
\hline Variabel & r Hitung & r Kritis & Kriteria \\
\hline Kualitas Aplikasi & 0,919 & 0,600 & Reliabel \\
\hline Kinerja Karyawan & 0,920 & 0,600 & Reliabel \\
\hline Pelayanan Kosumen & 0,782 & 0,600 & Reliabel \\
\hline
\end{tabular}

Sumber: Hasil Data Olah Kuesioner, 2018

Berdasarkan Tabel 4 dapat diketahui bahwa variabel Kualitas Aplikasi memiliki nilai r 0,919, variabel kinerja karyawan memiliki nilai r 0,920, dan variabel pelayanan konsumen memiliki nilai $r$ 0,782. Berdasarkan nilai tersebut maka ketiga variabel dalam penelitian ini dinyatakan reliabel karena $\mathrm{r}$ hitung $>\mathrm{r}$ kritis, $\mathrm{r}$ hitung $>0,600$.

\subsection{Uji Normalitas}

Uji normalitas digunakan untuk mengetahui apakah suatu data mengikuti sebaran normal atau tidak normal dengan menggunakan metode model regresi, variabel terikat dan variabel bebas keduanya mempunyai distribusi normal. Pengujian ini juga menggunakan bantuan software SPSS. 
Model regresi yang baik adalah memiliki distribusi data normal/mendekati normal. Cara untuk mengetahui normalitas adalah dengan melihat normal probability plot yang membandingkan distribusi kumulatif dan distribusi normal. Distribusi normal akan membentuk suatu garis lurus diagonal, dan plotting data akan dibandingkan dengan garis diagonal. Jika distribusi data adalah normal, maka garis yang memberikan data sesungguhnya akan mengikuti garis diagonalnya (Ghozali:2005).

\section{Pelayanan_Konsumen}

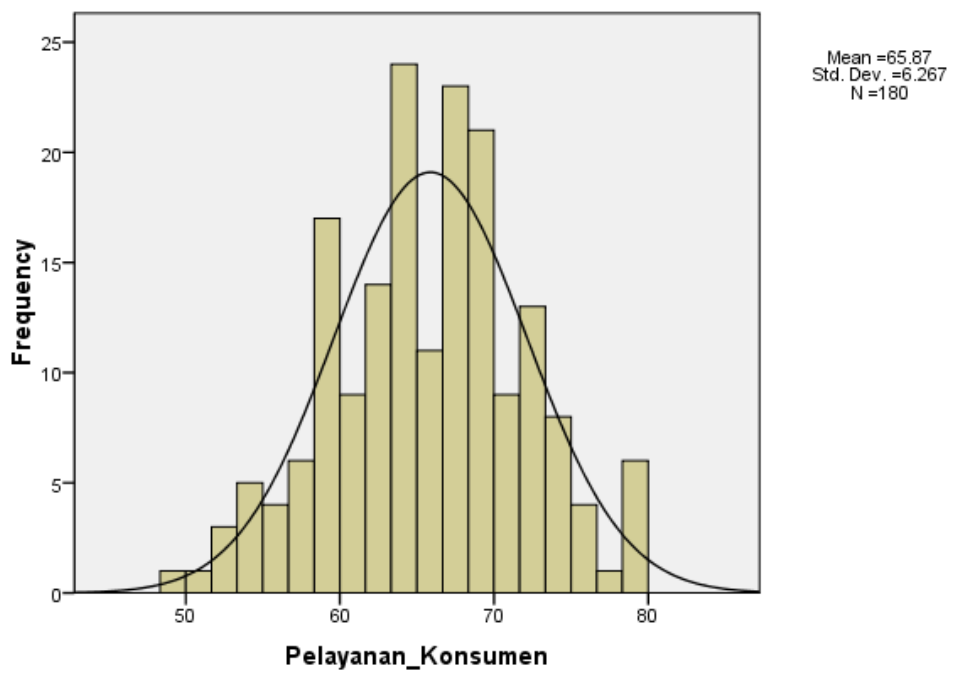

Gambar 1 Histogram Uji Normalitas Regresi Linear Berganda

Berdasarkan Gambar 1 dapat diketahui distribusi tersebut normal karena membentuk suatu garis lurus diagonal.

\section{KESIMPULAN}

Berdasarkan hasil perhitungan sudah peneliti lakukan, maka peneliti dapat mengambil kesimpulan sebagai berikut:

1. Kualitas Aplikasi di PT. Keboyoran Indah Utama Cikarang menunjukan kualitas dengan nilai yang sangat baik. Hal ini menunjukkan bahwa kualitas aplikasi yang harus terus diperhatikan ketepatan waktu akses, agar karyawan tidak lama menunggu sistem pada saat mau input data atau memerlukan informasi pada sistem tersebut.

2. Untuk variabel kinerja karyawan kerjasama harus diperhatikan agar tujuan sebuah perusahaan bisa tercapai.

3. Pelayanan konsumen pada PT. Keboyoran Indah Utama Cikarang memiliki nilai kriteria sangat puas untuk dimensi empati. Karyawan PT. Keboyoran Indah Utama Cikarang harus terus memperhatikan dan peduli akan kebutuhan dan keluhan dari konsumen agar konsumen merasakan pelayanan yang baik dari para karyawan sehingga konsumen tidak akan lari ke tempat service yang lain.

4. Adanya hubungan dan signifikan antara kualitas aplikasi terhadap kinerja karyawan berdampak pada pelayanan konsumen.

\section{DAFTAR PUSTAKA}

Hutahaean, Japerson. (2014). “Konsep Sistem Informasi”. Yogyakarta: Deepublish. Kadir, Abdul. (2014). Pengenalan Sistem Informasi Edisi Revisi. Yogyakarta: Andi.

Ghozali, Imam. (2005). Aplikasi Analisis Multivariate dengan SPS”. Semarang: Badan Penerbit UNDIP

Hair et al. (2010). Multivariate Data Analysis, Seventh Edition. Pearson Prentice Hall Alma, Buchari. (2013). Manajemen Pemasaran dan Pemasaran Jasa. Bandung: Alfabeta.

Moeheriono. 2010. Pengukuran Kinerja Berbasis Kompetensi. Bogor:Penerbit Ghalia Indonesia

Robbins, Stephen. (2006). Perilaku Organisasi. Prentice Hall, edisi kesepuluh Sabardini, 2006, "Peningkatan Kinerja Melalui Perilaku Kerja Berdasarkan Kecerdasan Emosional", Telaah Bisnis, Vol.7, No.1

Widodo, Agus., Honorata Ratnawati Dwi Putranti dan Nurchayati. (2016). Pengaruh Kualitas Sistem Aplikasi Dan Kualitas Informasi Terhadap Kepuasan Pengguna Sistem Aplikasi RTS 
Techno Xplore

ISSN: 2503-054X

Jurnal Ilmu Komputer dan Teknologi Informasi

Vol. 3 No: 2, Oktober 2018

(Rail Ticketing System) Dengan Kepercayaan Sebagai Variabel Mediasi, Studi Pada Penumpang “KAI” Ekonomi Operasi 4 Semarang.. Jurnal, Vol. 31 No. 2(Juli). 164 